\title{
Executive Control in Learning: Evidence for the Dissociation of Rule Learning and Associative Learning
}

\author{
Tengfei Wang', Karl Schweizer', and Xuezhu Ren ${ }^{3}$ \\ ' Department of Psychology and Behavioral Sciences, Zhejiang University, Hangzhou, China \\ 2 Department of Psychology, Goethe University Frankfurt, Frankfurt am Main, Germany \\ ${ }^{3}$ School of Education, Huazhong University of Science \& Technology, Wuhan, China
}

ABSTRACT

\section{KEYWORDS}

executive control,

working memory,

rule learning,

associative learning

The dual-process account and the propositional account of learning hold opposite views regarding the recruitment of higher-level processes in rule learning and associative learning. Taking an individual differences perspective, the current study focused on the relationship between rule learning and associative learning and investigated to what extent executive control accounts for rule learning and associative learning. Two studies were conducted. In Study 1, a sample of 184 university students completed paired associative learning and rule learning tasks, as well as measures of working memory capacity, short-term storage, and executive control. Theory-based bifactor models were used to achieve a purified representation of executive control. The results showed that the latent correlation between associative learning and rule learning was rather small. Executive control showed a substantial relationship with rule learning, whereas no significant link was found with associative learning. In Study 2, a sample of 211 university students completed a three-term contingency learning task and an executive control task. The results replicated the finding that executive control was not significantly related to associative learning. Taken together, these results suggest a dissociation between rule learning and associative learning in terms of their underlying processes, which supports the dual-process account of learning.

\section{INTRODUCTION}

The dual-process account of learning suggests that people learn in two distinct ways: by rule learning or by associative learning (McLaren et al., 2014). Rule learning comprises hypothesis testing and the induction of the rules underlying a problem. In contrast, associative learning requires the establishment of links between mental representations by detecting the co-occurrence of different events, and also by distinguishing these co-occurrences from irrelevant contingencies (Mackintosh, 1997; McLaren, Green, \& Mackintosh, 1994). Both types of learning play an important role for humans in acquiring knowledge and skills.
For example, children usually learn new words by associating them with possible objects, properties, or actions (McMurray, Horst, \& Samuelson, 2012). On the other hand, individuals mainly rely on the detection and application of underlying rules in solving mathematical problems (Morsanyi, McCormack, \& O'Mahony, 2018).

According to the dual-process account, one major difference between rule and associative learning concerns the involvement of ex-

Corresponding author: Xuezhu Ren, School of Education, Huazhong University of Science \& Technology, Wuhan, China. E-mail: renxz@hust.edu.cn 
ecutive control. Rule learning relies heavily on executive control that is likely to be recruited in rule induction (Sweller, 1994). In contrast, associative learning, that is, the automatic formation of links between stimuli, may occur without the recruitment of such cognitive processes, or to a minor degree only (McLaren et al., 2014). The dual-process account of learning, however, has been strongly opposed by researchers endorsing the propositional account of learning (Mitchell, De Houwer, \& Lovibond, 2009). According to the propositional account, both rule and associative learning depend on higher-level cognitive processes. Contrary to the dual-process account, suggesting that very little executive control is involved in associative learning, the propositional account claims that even the establishment of associations between stimuli or events is achieved by arriving at propositional knowledge, and that this process stimulates executive control. These differences lead to disagreement as to whether rule and associative learning are related to executive control to a similar extent or not (McLaren et al., 2014).

Executive control refers to the cognitive system that regulates the flow of thought and is responsible for implementing task goals (Norman \& Shallice, 1986). Executive control serves as an umbrella term that consists of multiple processes, such as inhibition, shifting, and updating. According to Miyake et al. (2000), inhibition refers to the process of deliberately suppressing external and internal stimuli or prepotent responses that may divert attention away from the task goal. Shifting is the process of flexibly switching between different mental operations, mental sets, or task rules. Updating is responsible for the replacement of old, non-relevant information with new, relevant, incoming information. Executive control has been vastly investigated in the theoretical framework of working memory (Baddeley, 1992). For example, Engle and Kane (2004) propose that executive control serves as a major component of working memory and plays a critical role in maintaining task-relevant information in the face of potential distractions (Engle, Tuholski, Laughlin, \& Conway, 1999; Kane, Conway, Hambrick, \& Engle, 2007). The executive control of working memory provides the outset for testing the dual-process and the propositional account of learning, since there are various theories relating working memory or executive control to learning. Furthermore, working memory is a well-known source of individual differences that enables using both the experimental and differential approaches to gain further insight into the cognitive mechanisms of learning.

Rule learning, according to both the dual-process and the propositional account, includes hypotheses testing and rule induction. Executive control may be activated in dealing with knowledge perceived as sets of abstract rules (Anderson, Fincham, \& Douglass, 1997; McLaren et al., 2014; De Houwer, Hughes, \& Barnes-Holmes, 2016). For example, according to the theory of skill acquisition elaborated by Anderson et al. (1997), executive control is recruited in producing abstract rules based on the properties of examples. The focus of attention has to be allocated to relevant properties, and it needs to be assured that the best possible rules or hypotheses are created and tested.

Results from recent empirical studies indicate a positive relationship between executive control and the efficiency of rule learning (e.g.,
Craig \& Lewandowsky, 2013; DeCaro, Thomas, \& Beilock, 2008; Rabi \& Minda, 2014; Ropovik, 2014; Wang, Ren, \& Schweizer, 2015). For example, Wang et al. (2015) investigated the relationship between executive control and rule-based category learning. Their results suggest that individuals with higher flexibility of mental shifting need fewer trials to infer the rules underlying the categorization of stimuli than those with lower flexibility. In another recent study on school-aged children, Ropovik (2014) examined how inhibition, selective attention, and working memory predicted the ability to learn problem-solving rules. The results showed that inhibition and selective attention contributed substantially to rule learning, and that their effects on learning were fully mediated by working memory. These results suggest that individuals who are better able to resist attentional interference can maintain more information in working memory so that they can identify and apply the rules more efficiently. In addition, Rabi and Minda (2014) revealed that inhibitory control was associated with performance in rule-based categorization in both children and adults. These findings are in line with both the dual-process and the propositional accounts of learning.

Contrary to the dual-process account assuming that associative learning may occur independently of executive control, the propositional account regards associative learning as the impact of pairing events in the form of propositional knowledge on behavior (Mitchell et al., 2009). Relations between the events need to be established in an effortful way in order to arrive at propositional knowledge. This view suggests that controlled mental processing such as executive control is necessary for associative learning. In addition, associative learning involves representing the relations of events that need to be further transferred to long-term memory. Individuals with higher working memory capacity are likely to be more efficient in employing memory strategies to consolidate the memory traces linking different mental representations, in preventing interference of irrelevant information at the time of encoding, and in retrieval of information than those with lower working memory capacity (Healey, Hasher, \& Campbell, 2013; Richardson, 1998; Unsworth \& Spillers, 2010).

Empirical studies have mainly focused on the relationship of associative learning with working memory capacity (e.g., Bender \& Raz, 2012; Kaufman, DeYoung, Gray, Brown, \& Mackintosh, 2009; Kaufman et al., 2010; Lilienthal, Tamez, Myerson, \& Hale, 2013; Tamez, Myerson, \& Hale, 2008, 2012). They have provided mixed findings so far. For example, the study by Tamez et al. (2008) demonstrated that working memory assessed by complex span tasks was moderately related to associative learning $(r=.59)$. There are also a series of aging studies indicating that age-related declines in the establishment of novel links between previously unrelated information are strongly related to age differences in working memory (Bender \& Raz, 2012; Naveh-Benjamin, Guez, \& Shulman, 2004). However, there are also a line of studies reporting contrary findings. For example, Kaufman et al. (2009) examined the prediction of general intelligence by associative learning, working memory, and processing speed. While the main finding was that associative learning accounted for unique variance in general intelligence, the study also reported a rather small correla- 
tion between measures of associative learning and working memory $(r=.22)$. This result was confirmed by another study showing that the latent correlation between associative learning and working memory was small and not significant (Kaufman et al., 2010). A more recent study focusing on the role of inhibition in associative memory revealed that older adults' associative memory deficits might be independent of inhibitory and other resource-demanding processes (Guez \& NavehBenjamin, 2016).

To summarize, the dual-process and propositional accounts of learning differ as to whether executive control is an essential ingredient of both rule learning and associative learning. There is already some evidence that executive control relates to both rule and associative learning. However, the evidence came from separate lines of studies focusing on either rule or associative learning, which cannot be directly compared with each other due to variations in samples and measures of executive control or learning. Furthermore, previous studies mostly focused on the relationship between overall working memory and learning, without further specifying the role of the executive control component of working memory in learning. Therefore, it remains unclear whether each type of learning is associated with executive control when the other components of working memory are eliminated.

The current study aimed to combine rule and associative learning within a single framework and investigated to what extent the executive control component of working memory contribute to rule learning and associative learning. According to the propositional account, both associative learning and rule learning are related to executive control, whereas the dual-process account predicts that rule learning relates to executive control while associative learning may not, or only to a minor degree, relate to executive control. Testing these hypotheses was expected to clarify the role of executive control in human learning and to help settle the aforementioned dispute.

To achieve these aims, two empirical studies were conducted. Study 1 employed a classic rule learning task to assess how participants acquired the rules underlying a set of exemplars and further used these rules to solve new problems (Anderson et al., 1997). Associative learning was measured by the classic paired associative learning task, in which a participant had to establish novel links between words (Schweizer \& Koch, 2002). Data on executive control were also collected. Study 2 was conducted to replicate the finding from Study 1 with respect to the relationship between associative learning and executive control. This relationship was examined further because the main dispute between the dual-process and the propositional account of learning lied in whether associative learning was related to executive control. Study 2 employed the three-term contingency learning task, which was more complex than the paired associative learning task (Kaufman et al., 2009).

\section{STUDY 1}

Study 1 collected data on rule learning, paired associative learning, working memory, short-term memory, and executive control from a sample of university students. A novel aspect of this study was that two different approaches were employed to represent executive control. The first approach was adapted from the seminal work of Engle et al. (1999). Executive control was represented as the residual part of working memory when the storage-related component was removed (see also Colom, Rebollo, Abad, \& Shih, 2006). In their bifactor models, the common variance shared by working memory and short-term memory tasks was specified as the storage component, and the residual variance of the working memory task as the executive control component. We used established tasks tapping working memory (i.e., the exchange task) and short-term memory (i.e., the memory scanning task), and represented executive control by means of the bifactor model. The second approach directly measured executive control using an established executive functioning task. The star counting task was modified so that the experimental condition required mental switching, while the control condition did not. The bifactor model was also used to separate the auxiliary processes from the shifting process.

\section{Method}

\section{PARTICIPANTS}

The sample consisted of 184 university students (63 males) aged between 18 and 40 years $(M=23.85, S D=5.05)$. They were all native speakers of German. Most of them received financial rewards for participation. A few of them got course credit.

\section{EXPERIMENTAL TASKS}

Rule learning task (RLT). This task was constructed on the basis of the classic rule-learning task by Anderson et al. (1997). Participants were first presented with several sets of exemplars. They were asked to infer the rules underlying the exemplars and subsequently applied these rules to solve problems in the testing phase (Schweizer \& Koch, 2002). The learning exemplars consisted of 32 arrays of symbols (either + or o) following one of five rules. These 32 arrays were grouped into five sets, each associated with a specific rule. Two sets implied the application of simple rules (labeled $G$ and $H$ ), and three sets (labeled as $J, K$, and $L$ ) implied complex rules. Sets $\mathrm{G}$ and $\mathrm{H}$ included four arrays, each comprising three symbols, while Sets J, K, and L included eight arrays, each comprising four symbols. The arrays within a set followed the same rule that determined the last symbol in each array. For instance, the four sets of arrays, oo $o, o++,+o o$ and +++ constituted the rule that the last symbol was identical to the second one. Table 1 presents the five rules of the task with descriptions and examples for each rule.

During the learning phase, participants were informed that there would be a test requiring them to reproduce the last symbol of each array while considering the other symbols within the array. Participants were further informed that the identification of the rule would facilitate learning considerably. The learning of each set was started by entering a specific rule code $(G, H, J, K$, or $L)$, immediately followed by one of the arrays associated with the rule. Participants could go up and down for inspecting different arrays by pressing either the up key or the down key, through which they could check their hypotheses 
TABLE 1.

Rule Learning Task Rules and Example Descriptions

\begin{tabular}{|c|c|c|}
\hline Type of rules & Description of the rules & Examples \\
\hline G & $\begin{array}{l}\text { Plus rule: if there was a }+ \text { in the array, } \\
\text { the correct answer was } a+.\end{array}$ & {$[\mathrm{o}+] \rightarrow+$} \\
\hline $\mathrm{H}$ & $\begin{array}{l}\text { Zero rule: if there was an o in the array, } \\
\text { the correct answer was an } 0 .\end{array}$ & {$[+o] \rightarrow o$} \\
\hline $\mathrm{J}$ & $\begin{array}{l}\text { Adjacent rule: if adjacent stimuli were } \\
\text { different, the correct answer was an o. }\end{array}$ & {$[\mathrm{o}+\mathrm{o}] \rightarrow \mathrm{o}$} \\
\hline K & $\begin{array}{l}\text { Border rule: if either the left or right } \\
\text { symbol was a + while the other two were } \\
\text { not, the correct answer was a }+ \text {. }\end{array}$ & {$[\mathrm{oo}+] \rightarrow+$} \\
\hline $\mathrm{L}$ & $\begin{array}{l}\text { Odd rule: if one or three symbols were } \\
+ \text {, the correct answer was a }+ \text {, otherwise } \\
\text { it was an } 0 \text {. }\end{array}$ & {$[\mathrm{o}+\mathrm{o}] \rightarrow+$} \\
\hline
\end{tabular}

regarding the rule underlying the set of arrays. The learning procedure was self-paced and lasted for $10 \mathrm{~min}$.

In the testing phase, each participant was presented with an answer sheet. There were five sets, each comprising four arrays of symbols and a specific rule $(G, H, J, K$, or $L)$. The last symbol of each array was missing. Participants were asked to determine what the last symbol should be according to this rule. No time limit was imposed on responding. The scores were the number of correctly solved arrays for each rule.

Associative learning task (ALT). This task was used to tap the ability of establishing associations between artificial words and assigned meanings (Schweizer \& Koch, 2002). It consisted of 20 pairs of artificial words and associated meanings. Each artificial word was composed of six or seven letters. The word did not exist in the German language, but was composed of familiar German syllables and could be pronounced by a native speaker of the German language easily. For example, the word Orkinol was defined as a mixture of salad oil and liqueur. The word Wezida was defined as a blended fabric of polyester and nylon.

In the learning phase, participants were allowed $5 \mathrm{~min}$ to learn 20 pairs of artificial words and their associated meanings. They were instructed to look through the list of words and assigned meanings by pressing either the $u p$ or down key. Whenever participants pressed a key, a combination of an artificial word and the assigned meaning appeared on the computer screen. After the learning phase, each participant was presented with an answer sheet with the same 20 artificial words and meanings that were seen during the learning phase. However, the meanings were switched between artificial words, so that half of the artificial words were paired with their correct meanings, and half were paired with incorrect meanings. The correct and incorrect test items were arranged randomly. The words and meanings were only used once so that there were no specific relationships among any of them. Participants were asked to determine whether the given pairing of meaning and word was correct according to the previously learned information. No time limit was imposed on responding. The responses to the items were recorded as binary data. Besides a total score, four subscores, each based on a subsection comprising five neighboring items, were computed.

Working memory task. The Exchange task (ET) was employed to measure working memory capacity (Schweizer, 2007). This task stimu- lated the simultaneous storage and exchange processes. Participants were asked to mentally reorder the serial positions of symbols. In each item, two arrays of the same four symbols with different orderings were presented. Participants had to mentally exchange the positions of adjacent symbols in one array until the sequence became identical to the other one and to maintain the number of exchanges simultaneously. They were instructed to press the response key after completing the reordering, and to enter the number of exchanges. The task included three treatment levels, reflecting the increasing demands on memory capacity. Participants had to exchange two, three, and four times in Treatment Level 1, 2, and 3, respectively. Each treatment level included 12 items. The total number of correctly completed items was computed for each treatment level.

Short-term memory task. This task was a modified version of the memory-scanning task (MST, Sternberg, 1966) that asked participants to memorize a sequence of letters. Each trial began with a screen prompting the participants to press the space bar to start, followed by a blank screen lasting for $1 \mathrm{~s}$. A series of letters were successively presented on the screen. Each letter appeared for $500 \mathrm{~ms}$. A probe letter was presented after an interval of $2 \mathrm{~s}$. Participants were asked to determine whether the probe letter was among the presented letters or not by pressing one of two buttons. The task consisted of three treatment levels, each including 18 trails. These three levels varied in the number of letters $(4,5$, or 6$)$ presented in each trial. The total number of correctly completed trials was computed for each treatment level.

Executive control task. The original star counting task (SCT) was adapted to tap executive control, particularly the mental shifting process (De Jong \& Das-Smaal, 1995; Ren, Altmeyer, Reiss, \& Schweizer, 2013). The task asked participants to count signs in a forward or backward direction. Each trial started with the presentation of a stimulus including a starting number and a fixation point surrounded by 8 dots on the screen for $400 \mathrm{~ms}$. Following the disappearance of the starting stimulus, a varying number $(6,8,10$, or 12$)$ of stimuli appeared successively, each for $400 \mathrm{~ms}$. These stimuli were similar to the starting stimulus, but one of the 8 dots was replaced by a plus or a minus sign. The starting number was to be increased by one for a plus sign and decreased by one for a minus sign. Participants were asked to enter the final result.

This task included two treatment levels. There were only plus signs in each trial of the first level while both plus and minus signs were randomly presented in the second level. The second level was assumed to impose higher demands on executive control, especially on the mental shifting process. Participants first completed 12 trials of the first level and then 12 trials of the second level. We computed three subscores for each level by combining the results of four trials so that the composite scores could be used as manifest variables in modeling analyses.

Apparatus and procedure. Participants were tested in pairs in a quiet lab. The working memory, short-term memory and executive control tasks were computerized tasks. For the learning tasks, learning materials were presented on a computer, but the responses were written on an answer sheet. To minimize method variance due to the order effect, the measures were administered in the same following order 
across all participants: MST, ET, SCT, AL, and RL. Participants had an opportunity to take a short break between the tasks.

Modeling analyses. Modeling analyses were conducted by LISREL 8.8 on the basis of the covariance matrix (Jöreskog \& Sörbom, 2006). Parameters were estimated by means of the maximum likelihood method. Criteria recommended by DiStefano (2016) were used to evaluate the fit statistics. Specifically, the fit of a model was considered good (or acceptable) if $\chi^{2} / \mathrm{df} \leq 2(3), \mathrm{RMSEA} \leq .05(.08)$, SRMR $\leq .08$ (.10), and CFI $\geq .95(.90)$.

\section{RESULTS}

Table 2 presents the descriptive results for each set of the associative learning task and the rule learning task, each treatment level of the memory scanning task, the exchange task, and the star counting task, as well as the intercorrelations among the variables.

A confirmatory factor analysis model examining the latent correlation between associative learning and complex learning was investigated first. As shown in Figure 1, the latent variable representing associative learning was derived from the four subscores of the paired associative learning task, and the latent variable representing rule learning from the five subscores of the rule learning task. The model showed a good fit to the data, $\chi^{2}(26)=31.87, \mathrm{p}=.20, \chi^{2} / \mathrm{df}=$ $1.23, \mathrm{RMSEA}=.035, \mathrm{SRMR}=.057$, and CFI $=.97$. The latent correlation between associative learning and rule learning was not significant $(r=.16, t=1.42, p>.05)$, suggesting a dissociation of these two types of learning.

Executive control was represented differently in the two approaches. First, the executive control factor was derived from the residual variance of the exchange task by removing the variances shared by the memory scanning task and the exchange task. The shared variance was assumed as the storage-related factor (see Figure 2). Both executive control and the storage-related factor were allowed to predict associative learning and rule learning. The prediction model showed a good fit, $\chi^{2}(83)=84.89, \mathrm{p}=.42, \chi^{2} / \mathrm{df}=2.02, \mathrm{RMSEA}=.011, \mathrm{SRMR}=.056$, and $\mathrm{CFI}=.99$. As shown in Figure 2, executive control was moderately related to rule learning $(r=.40, t=3.19, p<.05)$, but not to associative learning $(r=-.07, t=-.73, p>.05)$. The difference between the magnitude of these two correlations was significant $(Z=4.68, p<.01)$. In addition, the storage-related factor was related to associative learning $(r=.27, t=2.34, p<.05)$ and rule learning $(r=.36, t=2.62, p<.05)$ at a small level.

In the second approach, a particular key executive process, that is, the mental shifting, was represented by the SCT. We also examined a bifactor model, in which one factor was derived from the subscores across the two treatment levels of the SCT while the other factor was linked to the subscores of the second treatment level. Since only the second level involved switching operations between forward and backward counting, this factor was assumed to reflect the core process of mental shifting, whereas the other latent variable represented all auxiliary processes associated with the task, such as the perception of stimuli, the counting process, the general processing speed, and so forth (see Figure 3). These two latent factors were also linked to associative and rule learning. This prediction model showed a good fit to the data, $\chi^{2}(83)=83.02, p=.48, \chi^{2} / d f=1.73$, RMSEA $=.001$, $\operatorname{SRMR}=.050$, and CFI $=1.00$. As shown in Figure 3 , the shifting process was moderately related to rule learning $(r=.50, t=3.32, p<$ $.05)$, but the link to associative learning was small and not significant $(r=.23, t=1.96, p>.05)$. The difference between the magnitude of these two links was significant $(Z=2.99, p<.01)$. In addition, the auxiliary factor of the SCT showed a small correlation with associative learning $(r=.30, t=2.75, p<.05)$.

\section{TABLE 2.}

Descriptive Statistics for All Study 1 Measures and Intercorrelations $(N=184)$.

\begin{tabular}{|c|c|c|c|c|c|c|c|c|c|c|c|c|c|c|c|c|c|c|c|c|c|c|}
\hline Measure & $M$ & $S D$ & 1 & 2 & 3 & 4 & 5 & 6 & 7 & 8 & 9 & 10 & 11 & 12 & 13 & 14 & 15 & 16 & 17 & 18 & 19 & 20 \\
\hline 1.ET-1 & 11.05 & 1.41 & - & & & & & & & & & & & & & & & & & & & \\
\hline 2.ET-2 & 9.64 & 2.31 & .23 & - & & & & & & & & & & & & & & & & & & \\
\hline 3.ET-3 & 7.52 & 2.78 & .37 & .46 & - & & & & & & & & & & & & & & & & & \\
\hline 4.MST-1 & 16.84 & 1.25 & .17 & .10 & .13 & - & & & & & & & & & & & & & & & & \\
\hline 5.MST-2 & 17.39 & .83 & .25 & .15 & .22 & .56 & - & & & & & & & & & & & & & & & \\
\hline 6.MST-3 & 15.78 & 1.34 & .08 & .16 & .16 & .40 & .43 & - & & & & & & & & & & & & & & \\
\hline 7. SCT1-1 & 3.74 & .58 & .05 & .12 & .15 & .23 & .05 & .25 & - & & & & & & & & & & & & & \\
\hline 8. SCT1-2 & 3.71 & .63 & .20 & .21 & .11 & .22 & .15 & .25 & .31 & - & & & & & & & & & & & & \\
\hline 9. SCT1-3 & 3.68 & .57 & .19 & .23 & .21 & .36 & .23 & .17 & .36 & .41 & - & & & & & & & & & & & \\
\hline 10. SCT2-1 & 3.17 & 1.04 & .21 & .17 & .19 & .36 & .32 & .41 & .26 & .25 & .20 & - & & & & & & & & & & \\
\hline 11. SCT2-2 & 3.21 & .96 & .11 & .09 & .03 & .39 & .24 & .30 & .36 & .31 & .32 & .48 & - & & & & & & & & & \\
\hline 12. SCT2-3 & 2.97 & 1.03 & .10 & .23 & .22 & .29 & .15 & .32 & .19 & .22 & .22 & .39 & .42 & - & & & & & & & & \\
\hline 13. ALT-1 & 3.70 & 1.18 & .19 & .18 & .15 & .04 & .06 & .05 & .10 & .10 & .11 & .21 & .20 & .16 & - & & & & & & & \\
\hline 14. ALT-2 & 4.21 & .84 & .06 & .15 & -.02 & -.07 & -.05 & .06 & .01 & .11 & -.05 & .10 & .14 & .16 & .37 & - & & & & & & \\
\hline 15. ALT-3 & 3.78 & 1.13 & .20 & .14 & .06 & -.01 & -.04 & .10 & .11 & .22 & .16 & .20 & .25 & .14 & .37 & .40 & - & & & & & \\
\hline 16. ALT-4 & 3.77 & 1.27 & .17 & .14 & .07 & .07 & -.05 & .02 & .18 & .08 & .19 & .17 & .11 & .15 & .52 & .37 & .51 & - & & & & \\
\hline 17. RLT-1 & 3.26 & .91 & .16 & .06 & .18 & .22 & .25 & .25 & .09 & .15 & .05 & .22 & .16 & .23 & .16 & .04 & .14 & .09 & - & & & \\
\hline 18. RLT-2 & 3.09 & 1.11 & .06 & .08 & .10 & .15 & .21 & .24 & .04 & -.01 & .06 & .19 & .13 & .14 & .10 & -.06 & -.05 & -.08 & .36 & - & & \\
\hline 19. RLT-3 & 2.53 & 1.16 & .01 & .03 & .15 & .12 & .11 & .12 & .01 & .04 & .09 & .12 & .16 & .27 & .09 & .10 & .10 & .10 & .20 & .24 & - & \\
\hline 20. RLT-4 & 2.21 & 1.28 & -.01 & .01 & .04 & .02 & .10 & .11 & -.02 & .13 & .10 & .03 & .12 & .12 & .09 & .09 & .12 & .05 & .11 & .09 & .22 & - \\
\hline 21. RLT-5 & 2.36 & 1.33 & .07 & .13 & .18 & .02 & .12 & .17 & .01 & .08 & .02 & .11 & .01 & .08 & -.02 & .01 & -.07 & -.04 & .14 & .07 & .12 & .15 \\
\hline
\end{tabular}

Note. ET $=$ Exchange test, MST = Memory scanning task, SCT = Star counting task; ALT = Associative learning task, RLT = Rule learning task; Correlations larger than .15 are significant at the .05 level. 


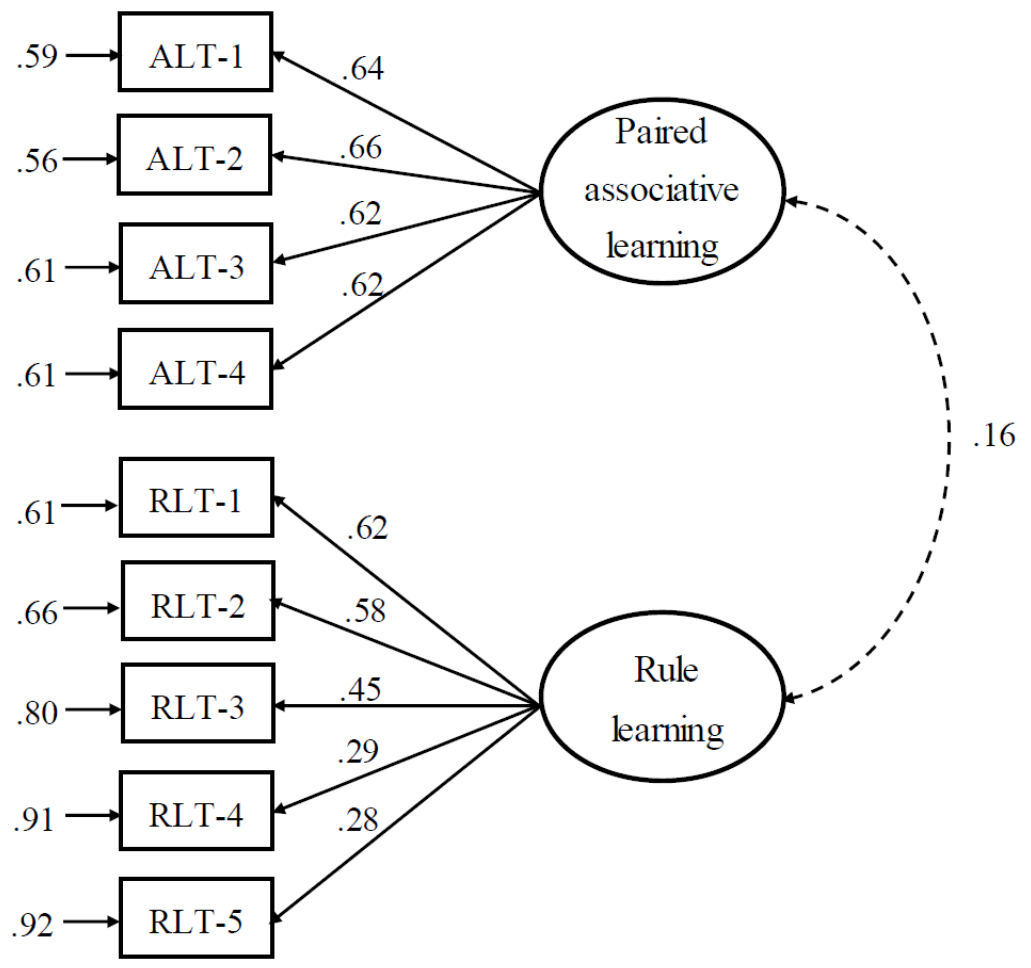

FIGURE 1.

The confirmatory factor model including paired associative and complex learning as latent variables with standardized loadings and error variances. ALT- $i=$ a subscore of the associative learning task; $R L T-i=$ a subscore of the rule learning task.

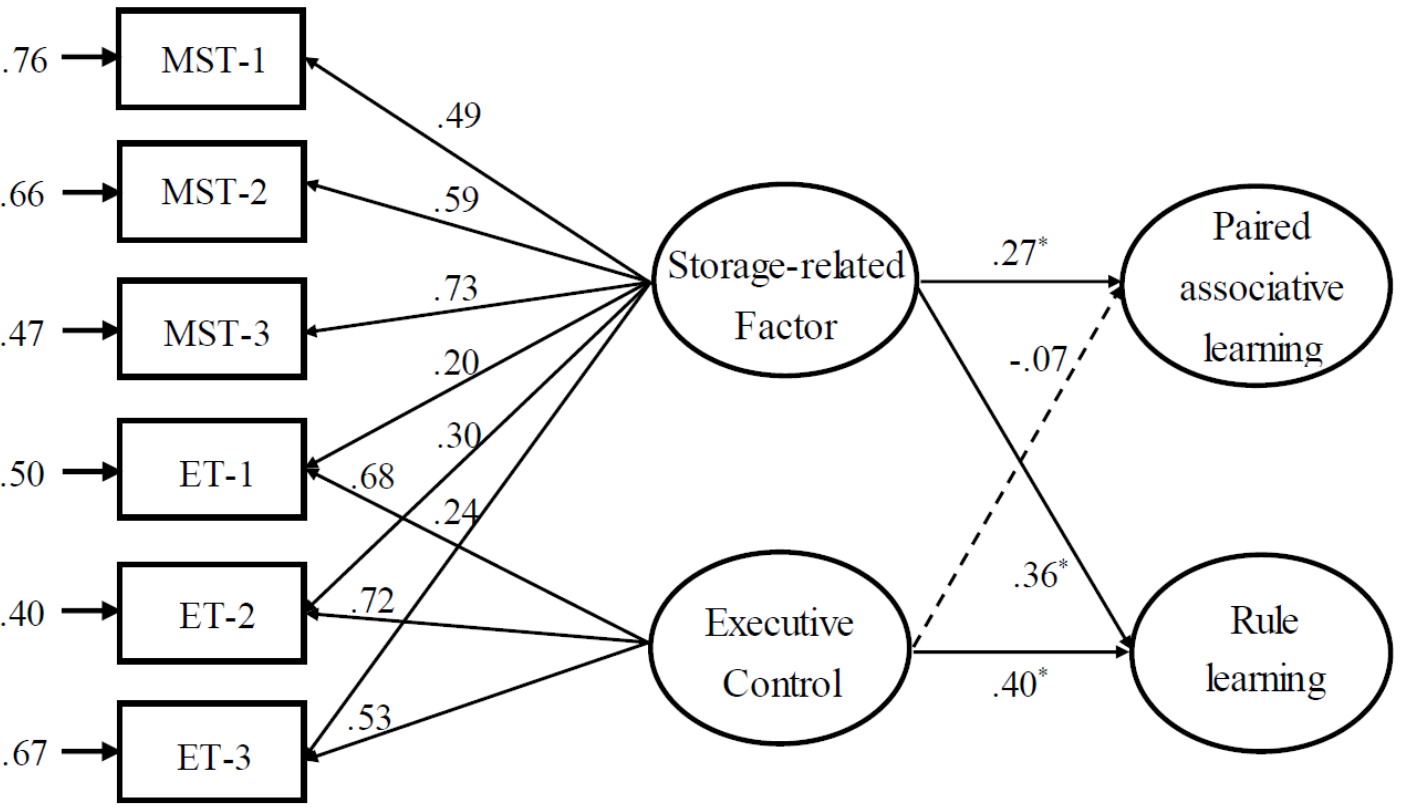

|FIGURE 2.

The prediction of associative learning and rule learning by the storage-related factor represented by the common variance in the memory scanning task and the exchange task, and by executive control represented by the residual variance in the exchange task. MST- $i=$ the score of the $i$-th level of the memory scanning task; ET- $i=$ the score of the $i$-th level of the exchange task. Solid lines represent significant links and dotted lines - nonsignificant links. * $p<.05$. 


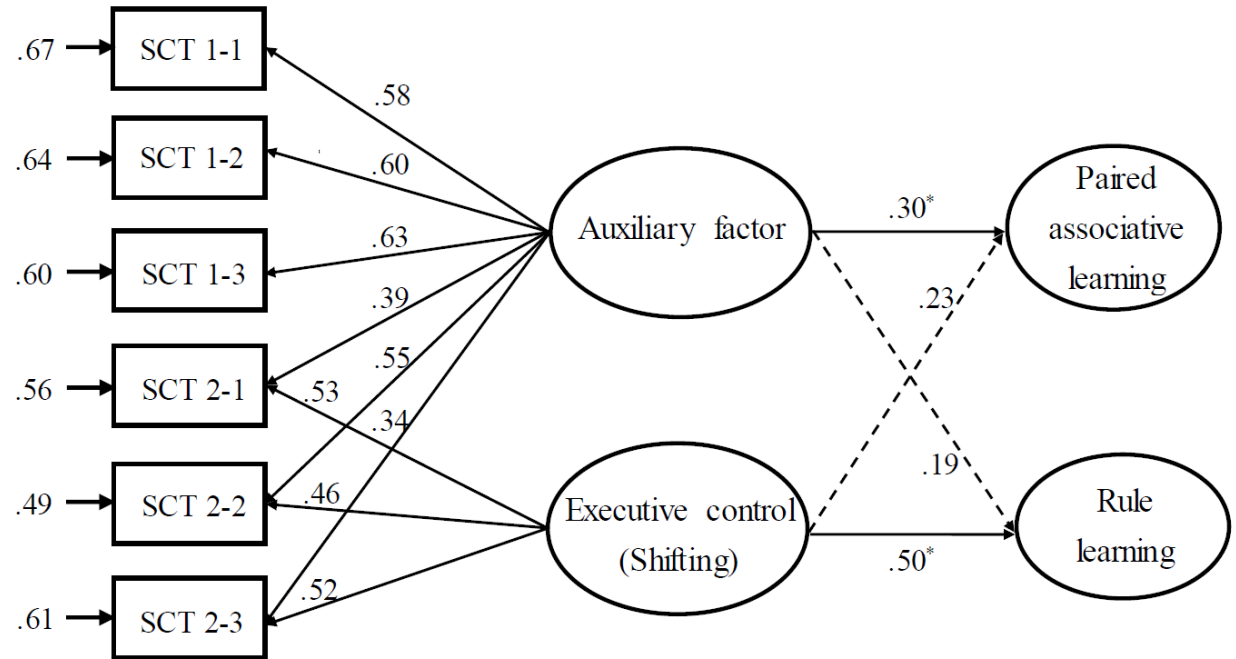

FIGURE 3.

The prediction of paired associative learning and rule learning by the auxiliary factor and the executive control process of the star counting task. SCT $i-k=$ the $k$-th composite score of the star counting task at the $i$-th treatment level. ${ }^{*} p<.05$.

\section{STUDY 2}

Since the dual-process account and the propositional account of learning hold different views on the relationship between associative learning and executive control, Study 2 investigated whether the findings obtained based on the paired associative learning task could be generalized to another associative learning task, the three-term contingency learning task (Kaufman et al., 2009). This study comprised data on associative learning and executive control, which was measured by a modified version of the star counting paradigm (De Jong \& Das-Smaal, 1995).

\section{Method}

\section{PARTICIPANTS}

A total of 211 undergraduate students participated in this study. There were 98 males and 113 females aged between 18 and 24 $(M=20.93, S D=1.14)$. Participants received financial rewards for participation.

\section{MEASURES}

Three-term contingency learning task (TCL). This task was used to tap the ability to form associations between unrelated words (Kaufman et al., 2009). There were four learning blocks, each followed by a test block. In the learning block, participants were presented with six cue words. Each cue word was associated with three prompts (the letters $A, B$, and $C$ ) and three corresponding outcome words. Each trial stated with a cue word appearing on the screen with the letters $A, B$, and $C$ listed underneath. Participants were prompted to successively press the letter keys. The letters $A, B$, and $C$ were associated with different outcome words. The duration of exposure to each association was self-paced (with the maximum length of exposure being $2.5 \mathrm{~s}$ ). Once all six cue words with 18 outcome words were presented, participants moved to the test block.

In the test blocks, the sequence of the cue words was identical to that of the learning blocks. Participants were presented with a cue word together with one of the letters. They were asked to type in the outcome words. Both the feedback (Correct or Wrong) and the correct outcome words were presented after each response. A second learning block started immediately following the previous test block. The same cue-outcome words were presented in different orders across the four learning blocks. The percentage of correctly recalled words was computed for each block.

Star counting task (SCT). The original SCT (De Jong \& Das-Smaal, 1995) was modified to tap multiple executive processes. Participants were asked to count the stars forward or backward from a starting number. The counting stimulus was a $14 \times 16 \mathrm{~cm}$ rectangle consisting of a number of stars with plus, minus, and slash signs between them. The plus and minus signs denoted the direction (forward and backward) in which the following stars should be counted. The slashes were distractors and were to be ignored during counting.

Each trial started with a starting number appearing in the center of the screen for $1 \mathrm{~s}$, followed by a counting stimulus. Participants had to count the stars from left to right and from top to bottom as quickly and as accurately as possible. The time limit for each counting was 40 $s$ and participants were asked to press the Enter key as soon as they finished. The stimulus disappeared from the screen when participants responded within the time limit or when the time ran out. Participants had to enter the final counting number into an input box. There were three treatment levels, each consisting of 12 trials. As shown in Figure 4 , the first level included only the plus signs while the second level consisted of plus and minus signs randomly. In the third level, there were both plus and minus signs, but the meaning of the signs was reversed, that is, a plus sign denoted backward counting while a minus sign de- 


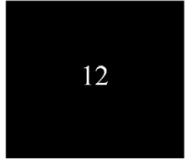

A FIGURE 4

Illustration of the star counting task. Panel A: starting number. Panel B: stimulus with only plus signs in the first treatment level. Panel C: stimulus with both plus and minus signs in the second treatment level. Panel D: stimulus with reversed meanings of plus and minus signs in the third treatment.

noted forward counting. The reversal of the rule was expected to pose extra demands on the inhibition of well-learned responses to the plus and minus signs. The opposite meaning in the third level was indicated by presenting stimuli with a white background, in contrast to the black background for the first and second levels. The sequence of trials from different treatment levels was arranged randomly. The percentage of correctly completed trials was computed for each level. We computed three subscores for each treatment level of the SCT by combining sets of four trials to obtain four composite scores serving as manifest variables in the modeling analyses.

\section{RESULTS}

Table 3 presents the descriptive results for each block of the threeterm contingency learning task and each treatment level of the SCT, as well as the intercorrelations among the variables.

We tested a three-factor model representing the executive processes underlying the star counting task. In this model, the shifting factor was derived from the subscores of the second and third treatment levels, since these two levels required the switching operations between forward and backward counting. The inhibition factor was linked to the subscores of the third treatment level, since only this level recruited the inhibition process. The auxiliary factor was loaded on all subscores of the three levels, representing the auxiliary processes stimulated in completing this task. The three factors were further linked to the associative learning factor derived from the four subscores of the threeterm contingency learning task. This model showed an acceptable fit, $\chi^{2}(53)=102.77, p<.001, \chi^{2} / \mathrm{df}=1.94, \mathrm{RMSEA}=.067, \mathrm{SRMR}=.041$, and CFI $=.95$. As shown in Figure 5 , there were no significant cor-

\section{TABLE 3.}

Descriptive Statistics for All Study 2 Measures and Intercorrelations $(N=211)$.

\begin{tabular}{cccccccccc}
\hline Measures & $M$ & $S D$ & 1 & 2 & 3 & 4 & 5 & 6 & 7 \\
\hline 1. SCT-1 & .89 & .12 & - & & & & & & \\
$2 . S C T-2$ & .80 & .16 & .19 & - & & & & & \\
3. SCT-3 & .78 & .20 & .34 & .49 & - & & & & \\
4. TCL-1 & .17 & .20 & .05 & .10 & .10 & - & & & \\
5. TCL-2 & .44 & .28 & .04 & .14 & .12 & .67 & - & & \\
6.TCL-3 & .60 & .30 & .12 & .22 & .20 & .54 & .85 & - & \\
7.TCL-4 & .71 & .28 & .05 & .21 & .15 & .47 & .75 & .88 & - \\
\hline
\end{tabular}

Note. SCT = Star counting task; $T C L=$ Three-term contingency learning task.

Correlations larger than .14 are significant at the .05 level. relations between associative learning and the three factors of the SCT (Auxiliary: $r=.19, t=1.79, p=.07$; Shifting: $r=.21, t=1.84, p=.07$; Inhibition: $r=-.02, t=-.15, p=.88)$.

\section{DISCUSSION}

The starting point of this study was the theoretical dispute over whether associative and rule learning shared the same underlying cognitive processes. According to the existing theoretical and empirical evidence, executive control was proposed as a potential source that may contribute to both types of learning. Therefore, in this study, we examined the relationship of executive control with rule and associative learning. The results from Study 1 showed that paired associative learning shared virtually no variance with rule learning, suggesting that these two types may represent different ways of learning. Furthermore, executive control was substantially related to rule learning, whereas no significant relationship was found between executive control and paired associative learning. The insignificant correlation between executive control and associative learning was confirmed by Study 2, based on different samples and different measures of associative learning.

Executive control was substantially associated with rule rather than with associative learning. This pattern was consistently observed when executive control was either represented by the residual part of working memory after the storage-related processes were stripped off or represented by the process of shifting attention across different mental operations. The observation of a substantial relationship between executive control and rule learning was not surprising, given that executive processes are mostly recruited to flexibly switch one's attention from invalid features of examples to valid features during the hypotheses testing procedure. In addition, executive control is crucial for inhibiting the interference of invalid rules so that valid rules can be maintained temporarily for further applications (Rabi \& Minda, 2014; Wang et al., 2015). This finding was consistent with the hypothesis according to both the dual-process and propositional accounts of learning.

The lack of a relationship between executive control and associative learning observed in both Study 1 and 2 suggested that executive processes played a rather limited role in associative learning. This was consistent with the dual-process account, in which mental links between representations are usually formed passively and automatically as a direct consequence of contiguous pairings of stimuli, without additionally resorting to executive processes (McLaren et al., 2014). While this result was consistent with the findings by Kaufman et al. $(2009,2010)$, it contradicted previous studies that reported substantial correlations between associative learning and working memory tasks (Tamez et al., 2012; Bender \& Raz, 2012). One reason for this inconsistency may be due to the variations in the measures of associative learning. For example, Tamez et al. (2012) used not only the verbal three-term contingency learning task, as Kaufman et al. (2009) did, but also the visual and spatial learning tasks. The modality of the learning task may affect the involvement of executive control during encoding and retrieval of the information. Furthermore, most of the previous studies did not differentiate executive control from working memory 


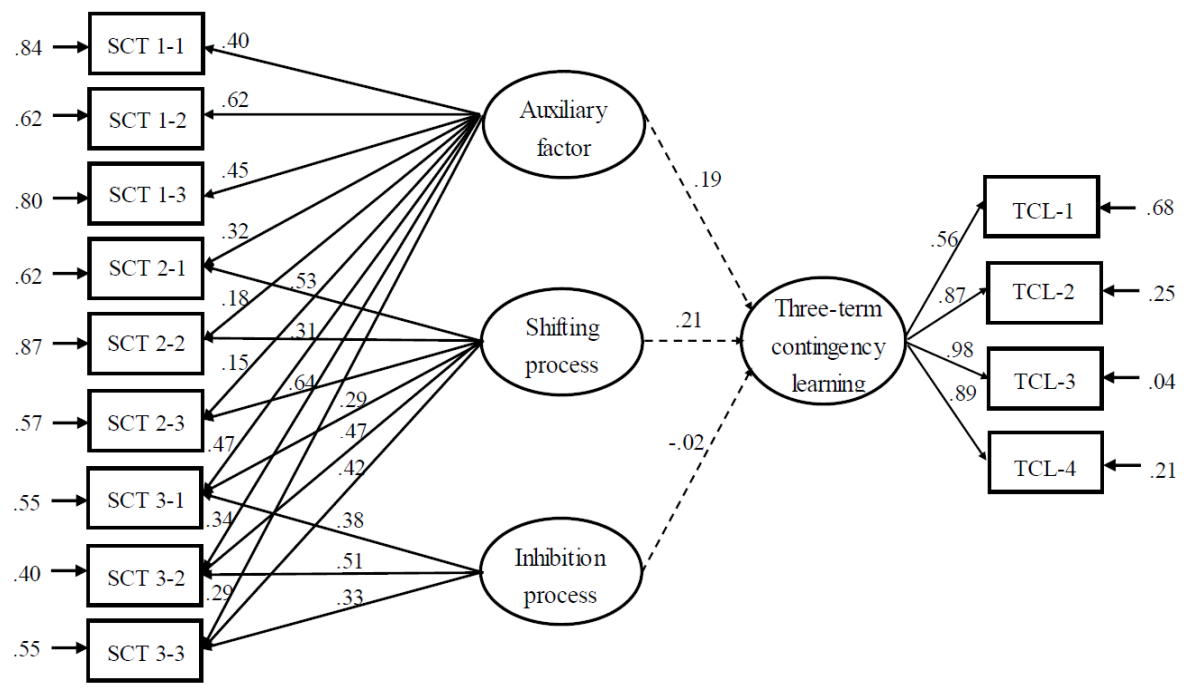

FIGURE 5.

The prediction of three-term contingency learning by the auxiliary factor, the shifting and inhibition processes of the modified star counting task. None of the path coefficients were significant.

that was usually assessed by the complex span tasks. It is thus unclear whether executive control contributes to associative learning when the other components such as storage-related processes are partialed out. By achieving a purified representation of executive control, the current study reveals that executive control plays a limited role in the establishment of links between mental representations. Taken together, our finding adds to the evidence supporting the dual-process account of learning, which assumes that associative learning seldom relies on higher-level mental processing.

At this point, it should be noted that the storage-related factor derived from the two memory tasks was significantly related to both rule and associative learning, although the magnitude of the coefficients was small. This suggests that storage capacity is also important for acquiring abstract rules. Such a result is in line with the theoretical account that skill acquisition starts from the encoding and maintenance of specific exemplars, which are necessary for developing hypotheses regarding the general pattern underlying those exemplars (Anderson et al., 1997; Rabi \& Minda, 2014; Ropovik, 2014). The significant link between the storage factor and associative learning was in line with the view that individuals with higher working memory capacity have the advantage of consolidating their memory traces binding different mental representations (Richardson, 1998; Unsworth \& Spillers, 2010).

Several limitations of the current study should be mentioned. First, only one experimental task was used to assess rule learning. Since the magnitude of the correlations between executive control and leaning is likely to be affected by a variety of factors, such as the types of tasks used and the characteristics of the sample, we are cautious in generalizing our findings. The current findings should be validated in future studies by applying more tasks to tap rule learning, so that the results of this study can be generalized to other paradigms of learning and executive control. Second, this study mainly adopted a differential approach investigating the relationships of executive control with rule learning and associative learning. Within this approach, the two types of learning were assessed by different measures according to established paradigms. In order to minimize the variation in learning tasks, an alternative approach may be to employ the discrimination learning paradigm (cf., Mutter, Haggbloom, Plumlee, \& Schirmer, 2006), in which both associative and inductive reasoning processes are involved and might be separated experimentally from each other. Future research may use this paradigm to isolate associative learning and rule learning and to examine how they are related to executive processes.

\section{ACKNOWLEDGEMENTS}

This research was supported by the Zhejiang Provincial Natural Science Foundation of China (No. LQ18C090001).

\section{REFERENCES}

Anderson, J. R., Fincham, J. M., \& Douglass, S. (1997). The role of examples and rules in the acquisition of a cognitive skill. Journal of Experimental Psychology: Learning, Memory, and Cognition, 23, 932-945. الميلس

Baddeley, A. D. (January, 1992). Working memory. Science, 255,

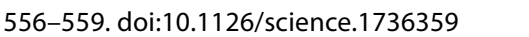

Bender, A. R., \& Raz, N. (2012). Age-related differences in recognition memory for items and associations: Contribution of individual differences in working memory and metamemory. Psychology and Aging, 27, 691-700. doi:10.1037/a0026714 المالسلسلس Colom, R., Rebollo, I., Abad, F. J., \& Shih, P. C. (2006). Complex span tasks, simple span tasks, and cognitive abilities: A reanalysis of key studies. Memory \& Cognition, 34, 158-171. doi:10.3758/

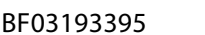

Craig, S., \& Lewandowsky, S. (2013). Working memory supports inference learning just like classification learning. The Quarterly Journal of Experimental Psychology, 66, 1493-1503. doi:10.1080 


\section{/17470218.2013.818703 الس}

De Jong, P. F., \& Das-Smaal, A. (1995). Attention and intelligence: The validity of the Star Counting Test. Journal of Educational Psychology, 87, 80-92. doi:10.1037//0022-0663.87.1.80 الس السلسل

DeCaro, M. S., Thomas, R. D., \& Beilock, S. L. (2008). Individual differences in category learning: Sometimes less working memory capacity is better than more. Cognition, 107, 284-294. doi:10.1016/j.cognition.2007.07.001 الس السلس

De Houwer, J., Hughes, S., \& Barnes-Holmes, D. (2016). Associative learning as higher-order cognition: Learning in human and nonhuman animals from the perspective of propositional theories and Relational Frame Theory. Journal of Comparative Psychology, 130, 215-225. doi:10.1037/a0039999 الف الس السلس

DiStefano, C. (2016). Examining fit with structural equation models. In K. Schweizer, \& C. DiStefano (Eds.), Principles and methods of test construction: Standards and recent advancements (pp. 166-193). Göttingen, Germany: Hogrefe.

Engle, R. W., \& Kane, M. J. (2004). Executive attention, working memory capacity, and a two-factor theory of cognitive control. In B. Ross (Ed.). The psychology of learning and motivation (Vol. 44, pp. 145-199). New York City, NY: Elsevier.

Engle, R. W., Tuholski, S. W., Laughlin, J. E., \& Conway, A. R. A. (1999). Working memory, short term memory, and general fluid intelligence: A latent-variable approach. Journal of Experimental Psychology: General, 128, 309-331. Wلس

Guez, J., \& Naveh-Benjamin, M. (2016). Proactive interference and concurrent inhibitory processes do not differentially affect item and associative recognition: Implication for the agerelated associative memory deficit. Memory, 24, 1091-1107. doi:10.1080/09658211.2015.1069852 الس الس الس الس

Healey, M. K., Hasher, L., \& Campbell, K. L. (2013). The role of suppression in resolving interference: Evidence for an age-related deficit. Psychology and Aging, 28, 721-728. doi:10.1037/ a0033003 الس الس

Jöreskog, K. G., \& Sörbom, D. (2006). LISREL 8.80. Lincolnwood, IL: Scientific Software International Inc.

Kane, M. J., Conway, A. R. A., Hambrick, D. Z., \& Engle, R. W. (2007). Variation in working memory capacity as variation in executive attention and control. In A. R. A. Conway, C. Jarrold, M. J. Kane, A. Miyake, \& J. N. Towse (Eds.), Variation in working memory (pp. 21-48). New York City, NY: Oxford University Press.

Kaufman, S. B., DeYoung, C. G., Gray, J. R., Brown, J., \& Mackintosh, N. (2009). Associative learning predicts intelligence above and beyond working memory and processing speed. Intelligence, 37, 374-382. doi:10.1016/j.intell.2009.03.004 السلسلس

Kaufman, S. B., DeYoung, C. G., Gray, J. R., Jiménez, L., Brown, J., \& Mackintosh, N. (2010). Implicit learning as an ability. Cognition,

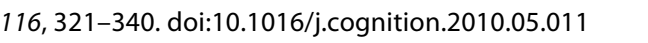

Lilienthal, L., Tamez, E., Myerson, J., \& Hale, S. (2013). Predicting performance on the Raven's Matrices: The roles of associative learning and retrieval efficiency. Journal of Cognitive Psychology, 25, 704-716. doi:10.1080/20445911.2013.791299 الس السلس
Mackintosh, N. J. (1997). Has the wheel turned full circle? Fifty years of learning theory, 1946-1996. Quarterly Journal of Experimental Psychology Section A, 50, 879-898. doi:10.1080/713755730 سلس

McLaren, I. P., Forrest, C. L. D., McLaren, R. P., Jones, F. W., Aitken, M. R. F., \& Mackintosh, N. J. (2014). Associations and propositions: The case for a dual-process account of learning in humans. Neurobiology of Learning and Memory, 108, 185-195. doi:10.1016/j.nlm.2013.09.014 السلسلس

McLaren, I. P. L., Green, R. E. A., \& Mackintosh, N. J. (1994). Animal learning and the implicit/explicit distinction. In N. C. Ellis (Ed.), Implicit and explicit learning of languages. London, England: Academic Press.

McMurray, B., Horst, J. S., \& Samuelson, L. K. (2012). Word learning emerges from the interaction of online referent selection and slow associative learning. Psychological Review, 119, 831-877. doi:10.1037/a0029872 سلسلس

Mitchell, C. J., De Houwer, J., \& Lovibond, P. F. (2009). The propositional nature of human associative learning. Behavioral and Brain Sciences, 32, 183-246. doi:10.1017/S0140525X09000855 السلسلس

Miyake, A., Friedman, N. P., Emerson, M. J., Witzki, A. H., Howerter, A., \& Wager, T. D. (2000). The unity and diversity of executive functions and their contributions to complex "frontal lobe" tasks: A latent variable analysis. Cognitive Psychology, 41, 49-100. doi:10.1006/cogp.1999.0734 سلسلس

Morsanyi, K., McCormack, T., \& O'Mahony, E. (2018). The link between deductive reasoning and mathematics. Thinking \& Reasoning, 24, 234-257. doi:10.1080/13546783.2017.1384760 |لسلس

Mutter, S. A., Haggbloom, S. J., Plumlee, L. F., \& Schirmer, A. R. (2006). Aging, working memory, and discrimination learning. Quarterly Journal of Experimental Psychology, 59, 1556-1566. doi:10.1080/17470210500343546 السلسلسل

Naveh-Benjamin, M., Guez, J., \& Shulman, S. (2004). Older adults' associative deficit in episodic memory: Assessing the role of decline in attentional resources. Psychonomic Bulletin \& Review, 11, 1067-1073. doi:10.3758/BF03196738 1ل

Norman, D. A., \& Shallice, T. (1986). Attention to action: Willed and automatic control of behavior. In R. J. Davidson, G. E. Schwartz, \& D. Shapiro (Eds.), Consciousness and self-regulation: Advances in research and theory (Vol. 4, pp. 1-18). New York City, NY: Plenum.

Rabi, R., \& Minda, J. P. (2014). Rule-based category learning in children: The role of age and executive functioning. PLoS One, 9, e85316. doi:10.1371/journal.pone.0085316 الس الس الس (2013).

Ren, X., Altmeyer, M., Reiss, S., \& Schweizer, K. (2013). Processbased account for the effects of perceptual attention and executive attention on fluid intelligence: An integrative approach. Acta Psychologica, 142, 195-202. doi:10.1016/j.actpsy.2012.12.007 الس السلسل

Richardson, J. T. E. (1998). The availability and effectiveness of reported mediators in associative learning: A historical review and an experimental investigation. Psychonomic Bulletin \& 
Review, 5, 597-614. doi:10.3758/BF03208837 |ل| |ل|

Ropovik, I. (2014). Do executive functions predict the ability to learn problem solving principles? Intelligence, 44, 64-74. doi:10.1016/j.intell.2014.03.002 السلسلسلس

Schweizer, K. (2007). Investigating the relationship of working memory tasks and fluid intelligence tests by means of the fixed-links model in considering the impurity problem. Intelligence, 35, 591-604. doi:10.1016/j.intell.2006.11.004 |لس

Schweizer, K., \& Koch, W. (2002). A revision of Cattell's Investment Theory: Cognitive properties influencing learning. Learning and Individual Differences, 13, 57-82. doi:10.1016/S10416080(02)00062-6 سلس سلس

Sternberg, S. (August, 1966). High speed scanning in human memory. Science, 153, 652-654. doi:10.1126/science.153.3736.652

Sweller, J. (1994). Cognitive load theory, learning difficulty, and instructional design. Learning and Instruction, 4, 295-312. doi:10.1016/0959-4752(94)90003-5 السلسلس
Tamez, E., Myerson, J., \& Hale, S. (2008). Learning, working memory, and intelligence revisited. Behavioural Processes, 78, 240-245. doi:10.1016/j.beproc.2008.01.008 السلسلس

Tamez, E., Myerson, J., \& Hale, S. (2012). Contributions of associative learning to age and individual differences in fluid intelligence. Intelligence, 40, 518-529. doi:10.1016/j. intell.2012.04.004 الفلسلس

Unsworth, N., \& Spillers, G. J. (2010). Variation in working memory capacity and episodic recall: The contributions of strategic encoding and contextual retrieval. Psychonomic Bulletin \& Review,

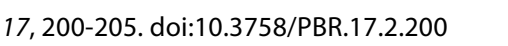

Wang, T., Ren, X., \& Schweizer, K. (2015). The contribution of temporary storage and executive processes to category learning. Acta Psychologica, 160, 88-94. doi:10.1016/j.actpsy.2015.07.003 المالس

RECEIVED 13.07.2018| ACCEPTED 14.01.2019 